

\section{EXPEDIENTE}

Universidade do Estado do Rio de Janeiro - UERJ

Instituto de Estudos Sociais e Políticos - IESP

\section{CADERNOS DE ESTUDOS SOCIAIS E POLÍTICOS}

www.e-publicacoes.uerj.br/index.php/CESP

\section{COMITÊ EDITORIAL}

Giovana Esther Zucatto, IESP-UERJ

Helio Cannone, IESP-UERJ

Marcelo Borel, IESP-UERJ

Marcia Rangel Candido, IESP-UERJ

Marina Rute Pacheco, IESP-UERJ

Mariane Silva Reghim, IESP-UERJ

Paulo Joaquim Da Silva Rodrigues, IESP-UERJ

Raul Nunes de Oliveira, IESP-UERJ

\section{CAPA, LAYOUT E DIAGRAMAÇÃO}

Marcia Rangel Candido

Raul Nunes de Oliveira

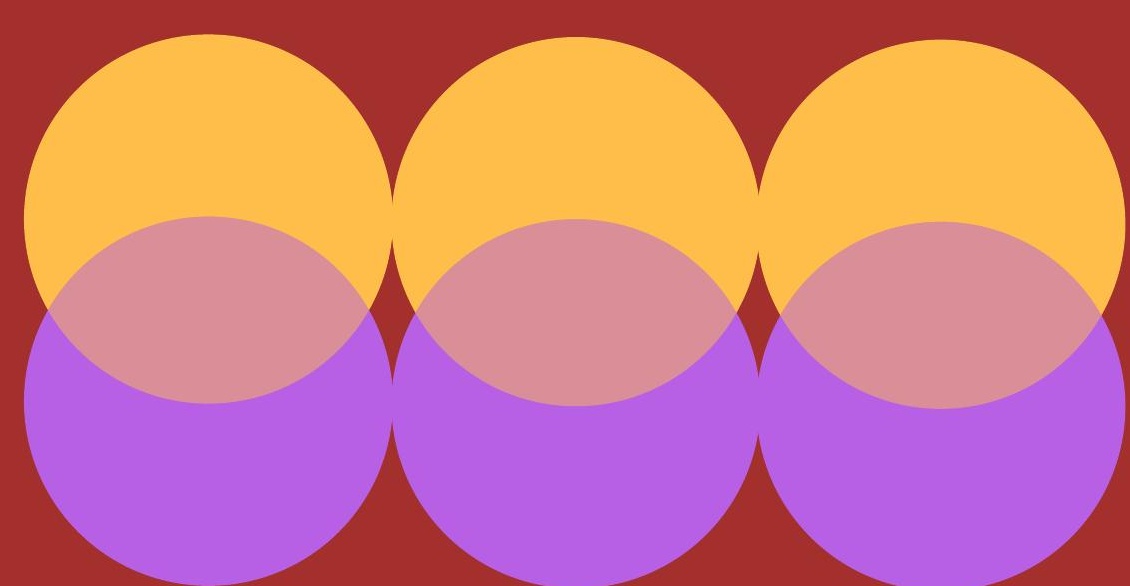


Apresentação

Mariane Silva Reghim e Marcelo Borel

Dossiê

As Expressões Do Racismo Institucional Nas Universidades Federais Do

Estado Do Rio De Janeiro: Mulheres Negras Trabalhadoras e Intelectuais

Cibele da Silva Henriques

Ressignificando As Raças: Os Deuses Pretos e Os Demônios Brancos No Discurso Nacionalista Preto Da Nação Do Islã nos Estados Unidos Da América

Rafael Filter Santos da Silva

Feminismo Negro e a Interseccionalidade de Gênero, Raça e Classe

Eunice Lea de Moraes Lucia Isabel Conceição da Silva

A Corporeidade e a Liberdade: Mulheres Negras e a Coragem De Ser

Joyce Gonçalves Restier da Costa Souza

\section{Artigos}

Os Governos Do PT e As Agências De Rating: Os Percalços De Treze Anos De Relação

Pedro Lange Netto Machado

Apropriação Cultural: Novas Configurações das Identidades na Era da Globalização

Bárbara Lopes Heleno e Rafaella Max Reinhardt

Resenha Crítica: O Segredo como Conceito Político: a propósito de Democracia e Segredo de Norberto Bobbio

Ronaldo Tadeu de Souza 


\title{
Feminismo Negro e a Interseccionalidade de Gênero, Raça e Classe
}

\author{
Black Feminism and the Intersectionality of Gender, Race and Class
}

\author{
Eunice Lea de Moraes ${ }^{1}$ \\ Lucia Isabel Conceição da Silva ${ }^{2}$
}

\section{RESUMO}

O artigo aborda a natureza interseccional do feminismo negro brasileiro como uma alternativa política para a compreensão e o enfrentamento das opressões de gênero, raça e classe pelas mulheres negras. Trata-se de um estudo teórico, baseado no pensamento de feministas afro-americanas e brasileiras, a saber, Angela Davis, Kimberlé Crenshaw, Patricia Hill Collins, Lélia Gonzalez, Sueli Carneiro e Luiza Bairros. O objetivo principal é debater a seguinte pergunta: como o feminismo interseccional das múltiplas dimensões de gênero, raça e classe influencia a luta das mulheres negras contra as dominações e opressões das quais historicamente são vítimas?

PALAVRAS-CHAVE: feminismo negro; interseccionalidade; gênero; raça; classe.

\begin{abstract}
The article addresses the intersectional nature of Brazilian black feminism as a political alternative for understanding and confrontation of the oppressions of gender, race and class by black women. This is a theoretical study, based on the thinking of African-American and Brazilian feminists, namely Angela Davis, Kimberlé Crenshaw, Patricia Hill Collins, Lélia Gonzalez, Sueli Carneiro and Luiza Bairros. The main objective is to discuss the following question: how does the intersectional feminism of the multiple dimensions of gender, race, and class influence the struggle of black women against the dominations and oppressions of which they historically are victims?
\end{abstract}

KEY WORDS: black feminism; intersectionality; gender; race; class.

1 Doutoranda em Educação pela Universidade Federal do Pará (UFPA). Professora da Faculdade de Educação do Instituto de Ciências da Educação da UFPA.

2 Doutora em Teoria e Pesquisa do Comportamento pela Universidade Federal do Pará (UFPA). Professora do Instituto de Ciências da Educação da UFPA. 


\section{INTRODUÇÃO}

A história das mulheres negras e de suas formas de resistência vem sendo construída a partir de aprendizados e lutas contra a dominação e a exploração de um sistema colonial escravista, patriarcal e patrimonialista repassado de geração a geração. Consequentemente, a formação de consciência de classe, de gênero e de raça tem constituído o caminhar dessas mulheres em diversas partes do mundo, inclusive no Brasil.

No que tange às mulheres afro-americanas, embora os movimentos de resistência datem de períodos anteriores, a última década do século XVIII mostra processos de organização coletiva para o alcance de poder econômico e político deste grupo feminino e suas comunidades. Em 1895, por exemplo, foi criado um movimento associativo, após as mulheres negras terem sido rechaçadas racialmente pelo movimento homogêneo branco, restrito aos direitos e às preocupações das mulheres brancas de classe média.

Esse processo demonstra a crítica fundamental das mulheres negras tanto em relação a um feminismo incapaz de perceber a dimensão racial imbricadas nas opressões de gênero, quanto em relação a um movimento de homens negros que, igualmente, não enxerga a dimensão de gênero na conformação das dominações raciais, ou de ambas nas opressões de classe. Esses movimentos pioneiros passam a chamar atenção para a necessidade de superar a compreensão das opressões a partir de estruturas excludentes de dimensões, atendo-se à forma como estas se sobrepõem.

O movimento associativo das mulheres negras possuía uma base política e ideológica contra os estragos que o racismo causava, além da discriminação de classe, evidenciado nas políticas organizativas das mulheres brancas. A definição central do movimento negro que marcava a diferença com o movimento hegemônico de mulheres era: "Nosso movimento de mulheres é um movimento de mulheres no sentido de que é conduzido e dirigido por mulheres pelo bem de mulheres e homens, pelo benefício de toda a humanidade [...]”. (DAVIS, 2017, p.15). Note-se que o referido movimento era aberto a todas as mulheres.

Com o decorrer do tempo, o movimento das mulheres negras traz para o movimento de mulheres uma grande contribuição às lutas que envolvem as questões atuais e do bem viver. 
Nos moldes do arcabouço político-ideológico do movimento afro-americano, as mulheres negras brasileiras iniciaram, a partir da década de 60 , um movimento de enfrentamento ao racismo. Sendo assim, ao pautarem a questão racial no movimento de mulheres, as ativistas brasileiras contribuem para que este avance teoricamente e enquanto prática social, bem como incorpore estudos mais recentes sobre a intersecção das categorias sociais de gênero, raça e classe.

As autoras feministas norte-americanas bell hooks, Kimberlé Crenshaw, Patricia Hill Collins e Angela Davis, precursoras e principais expoentes dos estudos sobre a questão racial, estabeleceram a interseccionalidade das categorias sociais de raça, gênero e classe, como um elemento fundamental que diferencia as trajetórias das mulheres. Essa abordagem se reproduz na produção de intelectuais negras brasileiras, como Lélia Gonzalez (a precursora dessa ideia no Brasil), Sueli Carneiro e Luíza Bairros, entre outras ativistas.

Nessa perspectiva, este artigo aborda a natureza interseccional do Feminismo Negro Brasileiro como uma alternativa política para a compreensão e o enfrentamento das opressões de gênero, raça e classe pelas mulheres negras. $\mathrm{O}$ estudo baseou-se no pensamento de feministas afro-americanas e brasileiras, como: Angela Davis, Kimberlé Crenshaw, Patricia Hill Collins, Lélia Gonzalez, Sueli Carneiro e Luiza Bairros.

Com base nas ideias das autoras elencadas, emergiu a pergunta que fundamentou esta investigação teórica: como o feminismo interseccional das múltiplas dimensões de gênero, raça e classe influencia a luta das mulheres negras contra as dominações e opressões das quais historicamente são vítimas?

Para tanto, discorre-se acerca da intersecção sexista, racista, classista dos sistemas de dominação e o feminismo negro, a fim de discutir e elucidar o significado desta compreensão interseccional para as práticas políticas atuais.

$\mathrm{Na}$ construção deste artigo, como procedimento metodológico, adotou-se o levantamento bibliográfico sobre a temática desenvolvida pelas autoras mencionadas. Após a leitura reflexiva desse acervo, depreenderam-se os processos teóricos e práticos da trajetória de resistência das mulheres negras as múltiplas opressões, culminando com a compreensão crítica sobre esses fatos.

O artigo está organizado da seguinte forma: a primeira seção aborda a interseção de sistemas opressores, ao tratar da interseccionalidade de gênero, raça e classe; a segunda seção descreve o feminismo negro e suas trajetórias de resistências; e a terceira seção delineia os aspectos do feminismo negro no Brasil. Nas considerações finais, pontuam-se algumas das 
principais contribuições e os desafios da institucionalidade do feminismo negro interseccional, além de se afirmar ser esta visão fundamental para a compreensão e o enfrentamento das opressões e desigualdades atuais.

\section{INTERSECCIONALIDADE DE GÊNERO, RAÇA E CLASSE}

Neste tópico, a finalidade não é propriamente efetuar uma descrição sobre sistemas que oprimem as mulheres negras, mas chamar a atenção para algumas ideias de significação sociológica e política dessa intersecção que baliza o universo do feminismo negro. Nesse sentido, serão destacadas referências de autoras sobre a temática, por se julgar suas concepções essencialmente importantes para os estudos acadêmicos.

Segundo Hirata (2014, p. 62), existe uma vasta literatura em língua inglesa e mais recentemente também em francês sobre interseccionalidade no que se refere ao uso desse termo. Pela primeira vez, em 1989, num texto da jurista afro-americana Kimberlé W. Crenshaw, interseccionalidade foi empregada para designar a interdependência das relações de poder de raça, sexo e classe.

Embora o uso do termo a ponto de se tornar bit concept, como denomina Elsa Dorlin (2012), e o franco sucesso alcançado por ele datem da segunda metade dos anos 2000, pode-se dizer que sua origem remonta ao movimento Black Feminism do final dos anos de 1970 (cf. Combahee River Collective, 2008; Davis, 1981; Collins, 1990; Dorlin, 2007), cuja crítica coletiva se voltou de maneira radical contra o feminismo branco, de classe média e heteronormativo.

O conceito de interseccionalidade foi cunhado por Kimberlé Crenshaw no final da década de 80 dentro dos marcos da luta feminista, mas, ao mesmo tempo, num contexto de crítica às noções homogeneizantes desta luta (CRENSHAW, 1989). Em princípio, sua formulação surge apoiada nas dimensões de raça e gênero, no contexto da violência contra mulheres de cor (utilizando o conceito da autora). Nesse momento cresciam as análises das contradições entre políticas de identidade e políticas de justiça social nos EUA, ao mesmo tempo em que criticava-se ao silêncio sobre as diferenças internas dentro de grupos de sujeitos. Um 
silêncio que excluía as mulheres negras do feminismo; um feminismo que em sua origem, sempre considerou apenas a vida e as experiências das mulheres brancas. A referida autora afirma:

\begin{abstract}
Centrarei as mulheres negras nesta análise a fim de contrastar a multidimensionalidade das experiências das mulheres negras com as análises de eixo-único que distorcem tais experiências. Esta justaposição, não apenas revelará como as mulheres negras são teoricamente excluídas, como também ilustrará como esta estrutura comporta sua própria limitação teórica que minam os esforços para ampliar as análises feministas e antirracistas ${ }^{3}$. (CRENSHAW, 2002. pp. 139-140).
\end{abstract}

Para Crenshaw (2002), esta compreensão via categorias mutuamente excludentes, além de construir análises equivocadas sobre racismo e sexismo, instaura obstáculos à construção de estratégias de enfrentamento das opressões. Dessa forma, a autora defende a necessidade de construção de referenciais teóricos que tratem de compreender o que efetivamente cria e sustenta as estruturas de desigualdades e opressões.

Assim, “o racismo, o patriarcado, a opressão de classe e outros sistemas discriminatórios criam desigualdades básicas que estruturam as possibilidades relativas" das pessoas e constituem instituições e políticas que as afetam (CRENSHAW, 2002, p. 177). Com a expressão “subordinação interseccional estrutural” (IDEM, 2002, p. 179), passa a referir-se às diversas possibilidades de intersecção de fatores que podem conformar sistemas de desigualdades. Sendo assim, opressões são fenômenos de grupo, resultantes de múltiplos sistemas de dominação e posicionamento social.

De acordo com Hirata, Crenshaw centraliza suas análises na intersecção entre raça e gênero, ao arguir parcialmente acerca de classe e sexualidade que "podem contribuir para estruturar suas experiências (as das mulheres de cor)". A intenção era expor as múltiplas identidades das mulheres (HIRATA, 214, p. 62).

Crenshaw subdivide a noção de interseccionalidade em duas categorias: uma estrutural e outra política. Estrutural por tratar da posição das mulheres negras nesta intersecção de raça e gênero, tendo como ponto central as violências e suas respostas. E política, ao focalizar as

\footnotetext{
3 No original: I will center Black women in this analysis in order to contrast the multidimensionality of Black women's experience with the single-axis analysis that distorts these experiences. Not only will this juxtaposition reveal how Black women are theoretically erased, it will also illustrate how this framework imports its own theoretical limitations that undermine efforts to broaden feminist and antiracist analyses.
} 
políticas feministas e as políticas antirracistas, que marginalizam a questão da violência em relação às mulheres negras. A autora destaca:

\begin{abstract}
A interseccionalidade é uma conceituação do problema que busca capturar as consequências estruturais e dinâmicas da interação entre dois ou mais eixos da subordinação. Ela trata especificamente da forma pela qual o racismo, o patriarcalismo, a opressão de classe e outros sistemas discriminatórios criam desigualdades básicas que estruturam as posições relativas de mulheres, raças, etnias, classes e outras. Além disso, a interseccionalidade trata da forma como ações e políticas específicas geram opressões que fluem ao longo de tais eixos, constituindo aspectos dinâmicos ou ativos do desempoderamento. (CRENSHAW, 2002, p.177).
\end{abstract}

Então, a interseccionalidade seria um modo de enlaçar as consequências da interação entre formas de subordinação, tais como sexismo, racismo e patriarcalismo. Poder-se-ia dizer que o feminismo interseccional estaria fundamentado no conceito de interseccionalidade de Crenshaw. Ângela Davis, feminista norte-americana autora do livro Mulher, raça e classe (2013), ao analisar o contexto social, histórico, crítico e contemporâneo da condição da mulher, em especial das mulheres negras norte-americanas, articula as lutas antiescravagista, anticapitalista, antirracista, feminista e aponta o papel das mulheres negras como central na luta contra as explorações e dominações.

Davis aborda a importância do estudo da relação entre distintas estruturas de opressão na vida de segmentos discriminados da população - especialmente as mulheres negras -, expondo o conceito de interseccionalidade a partir do entendimento de que as opressões de raça e gênero são a coluna vertebral da estrutura capitalista nas sociedades escravocratas.

Para ela, há uma relação inerente do racismo com a exploração praticada pelo sistema capitalista que naturaliza a exploração e a desconstrução do racismo, por meio da desnaturalização da questão de gênero e raça. Estabelece esta relação baseada na teoria marxista que propõe a desnaturalização das desigualdades sociais, contrapondo-se à ideia do senso comum de que as hierarquias são hereditárias e naturais.

No texto Racismo e Sexismo na Cultura Brasileira (1980), Lélia Gonzáles articula racismo e sexismo quando enfatiza questões específicas da mulher. Neste texto, acentua aspectos que continuam no debate atual das feministas negras e brancas - opressões de raça, classe e sexo conexão entre essas três configurações de dominação e exploração que há décadas é denunciada pela esquerda, no seu entender. 
Gonzáles trata as opressões de raça, sexo e classe para além da hierarquização. Classe, como determinante fundamental e princípio organizativo. Raça e sexo, como opressões apropriadas pelo sustentáculo do capitalismo. Portanto, ela ratifica o conceito de Interseccionalidade proposto por Kimberlé Crenshaw: interseccionalidade é a interseção das desigualdades de raça e de gênero.

No texto Nossos feminismos revisitados (1995), Luiza Bairros, ativista feminista negra brasileira, falecida em 2016, tece opinião semelhante à de Collins, em relação à intersecção das categorias sociais de raça e gênero, ao afirmar:

\footnotetext{
Raça, gênero, orientação sexual reconfiguram-se mutuamente formando [...] um mosaico que só pode ser entendido em sua multidimensionalidade. [...] Considero essa formulação particularmente importante não apenas pelo que ela nos ajuda a entender diferentes feminismos, mas pelo que ela permite pensar em termos dos movimentos negro e de mulheres negras no Brasil. Este seria fruto da necessidade de dar expressão a diferentes formas da experiência de ser negro (vivida através do gênero) e de ser mulher (vivida através da raça) o que torna supérfluas discussões a respeito de qual seria a prioridade do movimento de mulheres negras: luta contra o sexismo ou contra o racismo? - já que as duas dimensões não podem ser separadas. Do ponto de vista da reflexão e da ação política uma não existe sem a outra. (BAIRROS, 1995, p. 461).
}

Segundo Brittain e Maynard apud Juteau (2009, p. 94), o sexismo, o racismo e o classismo são formas de opressão que, embora possuam histórias diferentes, nem por isso deixam de agir de forma interdependente. Para Brittain, o conceito de interseccionalidade de Crenshaw possibilita a compreensão do ser mulher em sua múltipla forma, não como princípio unificador e, sim, como um princípio que permite visibilizar as relações de poder dos diversos sistemas opressões.

No texto Atualidade do conceito de interseccionalidade para a pesquisa e prática feminista no Brasil, Rodrigues (2013, p.7) conceitua interseccionalidade da seguinte maneira:

[...] a interseccionalidade constitui-se em ferramenta teórico-metodológica fundamental para ativistas e teóricas feministas comprometidas com análises que desvelem os processos de interação entre relações de poder e categorias como classe, gênero e raça em contextos individuais, práticas coletivas e arranjos culturais/institucionais. (RODRIGUES, 2013, p. 7).

Collins (2016) trabalha com as opressões de raça, classe, gênero, sexualidade e nação, por considerar que as mesmas se inter-relacionam, construindo reciprocamente sistemas de poder. Utiliza o termo "interseccionalidade" para explicar a sobreposição simultânea de múltiplas formas 
de opressão, considerando que as mulheres negras têm histórias únicas nas intersecções dos sistemas de poder. Embora em diferentes momentos sócio-históricos se amparem em formas e intensidades diferentes de opressão - podendo haver contextos em que o machismo é mais estruturante que o racismo, ou vice-versa -, a tese da natureza interligada da opressão permeia há tempo o pensamento feminista negro (IDEM, p. 08).

Após essas arguições centradas na interação de opressão de gênero, classe, etnia e identidade de gênero, torna-se importante abordar a trajetória do feminismo negro, uma vez que as mulheres negras são fortemente atingidas pelos sistemas opressores.

\section{FEMINISMO NEGRO E SUAS TRAJETÓRIAS DE RESISTÊNCIAS}

O Feminismo Negro surgiu nos Estados Unidos e tem como algumas importantes ativistas e pesquisadoras afro-americanas Kimberlé Crenshaw, Audre Lorde, bell hooks, Patrícia Collins, Ângela Davis, além de Ida Wells e Sojourner Truth, com inspirações na interseção das lutas abolicionistas e sufragistas. No Brasil, entre outras, destacam-se: a intelectual, política, professora e antropóloga brasileira Lélia Gonzáles; a filósofa, escritora e ativista do antirracismo e do movimento social negro brasileiro, Sueli Carneiro; e a professora, socióloga, feminista e ativista Luiza Bairros.

A antropóloga Jabardo (2012, p. 32-33), ao tratar das bases conceituais do feminismo negro, concorda com bell hooks na contraposição entre a famosa máxima de Simone de Beauvoir "não se nasce mulher, torna-se" e o também famoso discurso de Soujouner Truth - "não sou uma mulher?".

\footnotetext{
A questão que bell hooks retoma é a expressão de um sentimento coletivo que responde ironicamente às teorias feministas do gênero que surgiram da tese de Simone de Beauvoir, teorias que serviram para entender que a identidade coletiva e pessoal é socialmente reconstruída de forma precária e constante. No feminismo negro a identidade das mulheres é simultaneamente recuperada e reconstruída. Em face dos exercícios "construtivistas" do feminismo branco, o feminismo negro parte de uma não-categoria (não-fêmea). A única estratégia possível desde a negação é um exercício de desconstrução. As mulheres negras, buscam destruir a negação da qual foram excluídas da categoria de mulheres, para avançar, repensarem-se e reconstruírem-se a partir de outras categorias. Reconhecer as imagens de não-mulher como estratégias de hegemonia. [...] Para deixar de ser constituídas como objetos e pensar-se como sujeitos,
} 
elas precisaram tomar a palavra, recuperar a voz e gerar um novo discurso. Em definitivo, criar uma nova epistemologia. (Tradução livre das autoras). ${ }^{4}$

Jabardo identifica nessa contraposição uma divergência entre uma pretensa universalidade de mulher, subjacente à construção do feminismo hegemônico, e a reivindicação pelo reconhecimento de outros marcadores identitários (raça e classe), evidenciando outras possibilidades de "ser mulher" até então negadas ou excluídas do Feminismo.

Patrícia Hill Collins (2016, p.12), socióloga afro-americana estudiosa do Black Feminism, considera que foram as diversas experiências das mulheres afro-americanas em face da opressão que constituíram o ponto de partida do feminismo negro. Para ela, o pensamento feminista negro consiste em ideias produzidas por mulheres negras que elucidam um ponto de vista de e para mulheres negras.

[...] Primeiro, a definição sugere que é impossível separar estrutura e conteúdo temático de pensamento das condições materiais e históricas que moldam as suas vidas [...] Dessa forma, enquanto o pensamento feminista negro pode ser registrado por outras pessoas, ele é produzido por mulheres negras. Em segundo lugar, a definição assume que mulheres negras defendem um ponto de vista ou uma perspectiva singular sobre suas experiências e que existirão certos elementos nestas perspectivas que serão compartilhados pelas mulheres negras como grupo. Em terceiro lugar, embora o fato de se viver a vida como mulher negra possa produzir certas visões compartilhadas, a variedade de classe, região, idade e orientação sexual que moldam as vidas individuais de mulheres negras tem resultado em diferentes expressões desses temas comuns [...]. (COLLINS, 2016, p.12).

Ressalta-se também que, no texto Enegrecer o feminismo: a situação da mulher negra na América Latina a partir de uma perspectiva de gênero (2013), ao tratar da experiência histórica diferenciada e

4 La interrogación que retoma bell hooks es la expresión de um sentimiento colectivo que responde de forma irónica a las teorías feministas del género surgidas de la tesis de Simone de Beauvoir, teorías que sirvieron para comprender que la identidad colectiva y personal es reconstruida socialmente de manera precaria y constante. Desde el feminismo negro la identidad de la mujer es simultáneamente reclamada y reconstruida. Frente a los ejercicios «constructivistas» del feminismo blanco, el feminismo negro parte de una no-categoría (no-mujer). La única estrategia posible desde la negación es un ejercicio de de-construcción. Destruir la negación desde donde se ha excluido de la categoría de mujeres a las mujeres negras, para avanzar, repensarse y reconstruirse desde otras categorías. Reconocer las imágenes de nomujer como estrategias de hegemonía. [...]Para dejar de ser constituidas como objetos y pensarse como sujetos, tuvieron que tomar la palabra, recuperar la voz y generar un nuevo discurso. En definitiva, crear una nueva epistemología. 
qualificada das mulheres negras, a filósofa e ativista Sueli Carneiro questiona o mito da fragilidade feminina, ao perguntar: de qual mulher se está falando?

\begin{abstract}
Quando falamos do mito da fragilidade feminina, que justificou historicamente a proteção paternalista dos homens sobre as mulheres, de que mulheres estamos falando? Nós, mulheres negras, fazemos parte de um contingente de mulheres, provavelmente majoritário, que nunca reconheceram em si mesmas esse mito, porque nunca fomos tratadas como frágeis. Fazemos parte de um contingente de mulheres que trabalharam durante séculos como escravas nas lavouras ou nas ruas, como vendedoras, quituteiras, prostitutas... Mulheres que não entenderam nada quando as feministas disseram que as mulheres deveriam ganhar as ruas e trabalhar! (CARNEIRO, 2013, p. 01).
\end{abstract}

Portanto, o feminismo negro enquanto um movimento político de mulheres ativistas, tanto na esfera do debate de gênero quanto na luta antirracial, busca a transformação social a partir da compreensão de que o sexismo, a opressão de classes, a identidade de gênero e o racismo estão interligados. Há uma intersecção entre eles.

\title{
FEMINISMO NEGRO BRASILEIRO
}

No Brasil, o feminismo negro tem sua base teórica nos estudos de feministas negras norte-americanas, como bell hooks, Patrícia Hill Collins, Kimberlé Crenshaw e Ângela Davis, primordialmente. Não se pode esquecer o papel fundamental exercido pela professora e antropóloga brasileira Lélia Gonzáles, falecida em 1994, ao introduzir tais estudos no Brasil.

O feminismo negro brasileiro surge no final da década de 1970, a partir de reivindicações de mulheres negras feministas contra a prática do movimento feminista hegemônico, que não incluía a questão racial nas pautas reivindicatórias. As mulheres negras não tinham representatividade nesse movimento social hegemônico e consideravam-no uma face racista. Para elas, o movimento feminista tradicional operava dentro da concepção do mito da democracia racial, conceito utilizado pelo sociólogo Gilberto Freyre, na sua obra Casa-Grande \& Senzala, para descrever relações raciais harmoniosas no Brasil.

Entretanto, nas últimas quatro décadas, estudiosos como o sociólogo Florestan Fernandes, começaram a criticar esse conceito por esconder a situação de racismo no país. Tecem-se críticas também à ausência do Estado na empreitada de desconstruir este mito. Criado 
pelas elites coloniais - que ainda persistem na atualidade -, este mito é reforçado nas escolas, nos livros didáticos, na mídia etc. Assim,

A sociedade brasileira largou o negro ao seu próprio destino, deitando sobre seus ombros a responsabilidade de reeducar-se e de transformar-se para corresponder aos novos padrões e ideais de homem, criados pelo advento do trabalho livre, do regime republicano e capitalista. (FLORESTAN FERNANDES, 1978, p. 20).

As mulheres negras também percebiam que as relações de gênero no movimento negro eram sexistas e repressoras de sua autonomia, Impediam também que essas ativistas negras alcançassem posições de igualdade em relação aos homens negros. Ratifica-se essa constatação com o seguinte trecho:

[...] em conformidade com outros movimentos sociais progressistas da sociedade brasileira, o feminismo esteve, também, por longo tempo, prisioneiro da visão eurocêntrica e universalizante das mulheres. A consequência disso foi a incapacidade de reconhecer as diferenças e desigualdades presentes no universo feminino, a despeito da identidade biológica. Dessa forma, as vozes silenciadas e os corpos estigmatizados de mulheres vítimas de outras formas de opressão além do sexismo, continuaram no silêncio e na invisibilidade (CARNEIRO, 2003, p.118).

Logo, o feminismo negro é caracterizado como um movimento social e político, protagonizado pelo segmento de mulheres negras, com a finalidade de gerar visibilidade às suas reivindicações e direitos. Visa também a libertação de padrões patriarcais estereotipados de dominação e exploração racista e sexista da condição da mulher e do homem negro, estabelecidos na sociedade. O principal eixo articulador do feminismo negro seria o racismo e seu impacto sobre as relações de gênero, de acordo com Sueli Carneiro:

Portanto, para nós se impõe uma perspectiva feminista na qual o gênero seja uma variável teórica, mas como afirmam Linda Alcoff e Elizabeth Potter, que não "pode ser separada de outros eixos de opressão" e que não "é possível em uma única análise. Se o feminismo deve liberar as mulheres, deve enfrentar virtualmente todas as formas de opressão". A partir desse ponto de vista, é possível afirmar que um feminismo negro, construído no contexto de sociedades multirraciais, pluriculturais e racistas - como são as sociedades latino-americanas - tem como principal eixo articulador o racismo e seu impacto sobre as relações de gênero, uma vez que ele determina a própria hierarquia de gênero em nossas sociedades. (CARNEIRO, 2013, p.2).

O movimento feminista negro brasileiro tem protagonizado lutas importantes no enfrentamento às discriminações e desigualdades, desde, por exemplo, aquelas encabeçadas por 
Lélia González, passando por um ciclo de forte presença institucional e desenhos de políticas públicas, até os novos e mais recentes ciclos de ativismo feministas negros, que incluem mobilizações em massa, presença marcante do ativismo nas redes sociais, uma diversidade de coletivos periféricos e artísticos etc.

No centenário da abolição da escravidão no Brasil, dia 13 de maio de 1988, González e outras lideranças do movimento negro promoveram a Marcha Contra a Farsa da Abolição, no Centro do Rio de Janeiro. Promoveu também o Tribunal Winnie Mandela, na forma de júri simulado, formado por especialistas exponenciais de diversas áreas da sociedade civil, com o intuito de julgar e condenar a discriminação contra as mulheres negras brasileiras.

Nessa ocasião, lideranças feministas negras junto com Lélia González, como Luiza Bairros, Rosália Lemos, entre outras, realizaram o I Encontro Nacional de Mulheres Negras, na cidade de Valença no Rio de Janeiro, em 1988, tornando-se um marco importante na institucionalização do movimento de mulheres negras, sem significar uma ruptura ideológica com outros movimentos de resistência social.

A institucionalidade do movimento de mulheres negras tem se consolidado por meio de diversas ações das organizações para o fortalecimento do enfrentamento ao racismo, ao sexismo e para a defesa das políticas de promoção da igualdade racial e de gênero.

\footnotetext{
$\mathrm{Na}$ história recente do Brasil, sobressaem os avanços em termos de crescimento econômico, de ampliação da escolaridade e de redução da pobreza, resultantes do êxito de políticas sociais de cunho redistributivo e de valorização do salário mínimo. Estas, associadas à adoção de ações afirmativas, especialmente no campo da educação, produziram evidente melhoria nas condições de vida da população afro-brasileira. Contudo, verifica-se que esse quadro mais geral de aumento de oportunidades tem sido insuficiente para provocar uma significativa redução nas desigualdades raciais e de gênero. Isto pode ser atribuído à resiliência de mecanismos de reprodução de hierarquias e desigualdades sociais. Entre estes se destacam o racismo e o sexismo, que se combinam para delinear na sociedade visões que estereotipam e classificam capacidades e atributos de brancos e negros, de mulheres e homens, de modo a produzir condições diferenciadas de acesso a direitos e a oportunidades. (BAIRROS, 2013, p.13).
}

A ampliação das formas de organização e de luta dos movimentos negros, ao promover ações afirmativas e aprovar leis em favor da igualdade racial, tem produzido mudanças na inserção social da população negra, apontando um "novo" significado para ser negro ou negra. Um fato é o aumento na autodeclaração da identidade racial com ancestralidade africana, apontado na Pesquisa Nacional por Amostra de Domicilio de 2014 (PNAD, 2014). Segundo os 
dados, 53\% de brasileiros e brasileiras se declararam pardos (as) ou negros (as), diante de 45,5\% que se disseram brancos (as) ${ }^{5}$.

Entretanto, a população negra continua majoritariamente pobre. A população que formava o grupo $10 \%$ mais pobre, com renda familiar média mensal de $\mathrm{R} \$ 130$ por pessoa, continuava majoritariamente negra, significando 76\% em 2014. Esse número indica que entre os 10\% mais pobres do país, três em cada quatro pessoas são negras (IBGE, 2014), o que comprova a conformação racial das desigualdades e a raça serem elementos estruturadores das relações sociais, aí incluídas as relações econômicas, culturais e políticas (DAVIS, 1983; GUIMARÃES, 2006; 2002; 2016; GONZÁLEZ, 1988).

A situação não pode e nem deve ser pensada como simples herança escravocrata ou cultural, que atribui às mulheres e à população negra o último lugar nas esferas do poder econômico e político. Os resultados dessa discriminação e desigualdade vêm causando danos irreparáveis nesse segmento da população brasileira com a negação de direitos constitucionais de um Estado Democrático de Direito.

\section{CONSIDERAÇÕES FINAIS}

O objetivo deste artigo foi abordar a questão das intersecções de gênero, raça e classe dos sistemas de dominação no feminismo, fundamentado no pensamento de ativistas afro-americanas e brasileiras sobre feminismo negro e interseccionalidade, a fim de responder, a partir dos conceitos estudados, a indagação que norteou esta investigação teórica: como o feminismo interseccional das múltiplas dimensões de gênero, raça e classe influencia a luta das mulheres negras contra as dominações e opressões que historicamente são vítimas?

\footnotetext{
5 A pesquisa do IBGE notou que, desde 2007, a população brasileira que se autodeclara negra ou parda está aumentando. Há uma década, um maior número de pessoas se declara "preta". Em 2004, $51,2 \%$ dos brasileiros se diziam brancos diante de $42 \%$ pardos e $5,9 \%$ negros (totalizando $47,9 \%$ de negros e pardos), apontando para a predominância da população brasileira que se autodeclarava branca. Foi em 2007 que os números viraram, quando 49,2\% se disseram brancos, 42,5\% pardos e 7,5\% negros (totalizando $50 \%$ de negros e pardos). Desde então, o número de pessoas que se diz negro ou pardo só faz crescer (IBGE, PNAD, 2014).
} 
As leituras realizadas sobre a temática apontaram na direção de um pensamento feminista negro com formulação e atuação política própria, construído a partir da luta das mulheres negras pela sua libertação de todos os sistemas de opressões classistas, racistas e sexistas. Esse feminismo se alicerça na humanização que se contrapõe à desumanização imposta pelo racismo à população negra e pressupõe uma disputa de poder, contra hegemônico ${ }^{6}$, no combate aos poderes de sistemas exploradores e dominadores do capitalismo.

Os estudos assinalam que as mulheres negras continuam insistindo na necessidade de consolidação do entendimento das construções sociais de gênero perpassadas por hierarquias opressoras de classe, raça, identidade de gênero e cultural, como um aspecto que se constrói sobre suas diferenças de saberes, vivências e experiências de mulheres. Ao fincarem essa ideia da interseccionalidade, elas demonstram a maneira como o racismo e o sexismo estão intrinsecamente ligados à opressão de classe da sociedade capitalista.

Mediante o entendimento teórico acerca de feminismo negro interseccional, o movimento feminista negro brasileiro tem se constituído numa luta histórica de resistências política, ideológica, teórica e prática de enfrentamento ao racismo, ao sexismo e de construção de sua identidade como sujeito social coletivo. O referido movimento tem impulsionado a formação de organizações de mulheres negras, bem como subsidiado a criação de políticas sociais afirmativas e a aprovação de leis antirracismo.

A luta do movimento feminista negro brasileiro é também contra o genocídio da população negra, em especial da juventude, e contra a desigualdade no mercado de trabalho. Além disso, defende a erradicação da discriminação sexual, da cultura do estupro e da violência doméstica, bem como a efetivação de políticas públicas de saúde, os direitos humanos, e a descolonização dos corpos e das mentes para o alcance da liberdade, entre outras bandeiras de luta.

Os estudos teóricos e as práticas históricas do feminismo negro têm propiciado ao feminismo contemporâneo a visibilidade das subjetividades das diferenças de classe, de identidade de gênero e etnicidade do ser mulher, difundindo outro aspecto das discriminações e das desigualdades que separam as mulheres nos diversos contextos: econômico, político, cultural e ideológico, evidenciando uma relação sexista e racista.

6 É um conceito de estratégia político-cultural que procura deslocar o equilíbrio dos aparelhos privados de hegemonia e dos seus intelectuais na direção de um novo projeto político-social. (Novo Dicionário Político, vol.1,1992, p.22). 
Entretanto, as teorias feministas devem focalizar mais os novos sujeitos sociais que formam os feminismos contemporâneos e que balizam o ativismo político, principalmente, o oriundo da juventude feminista negra, revelado por jovens presentes nos diversos espaços de luta, resistência e de valorização da mulher negra. Percebe-se também a urgência de maior articulação dos estudos acadêmicos com os movimentos de mulheres negras para um entendimento mais qualificado quanto à teoria e à prática destes feminismos contemporâneos que desmistificam a heterogeneidade normativa do ser mulher.

Concorda-se com o pensamento de Patrícia Collins (2016, p.15) sobre o papel das mulheres negras intelectuais: produção de fatos e de teorias sobre a experiência de mulheres negras que elucidam o ponto de destas para outras mulheres negras. $\mathrm{O}$ argumento da autora é que a cultura desenvolvida por essas mulheres é básica para elaboração de referencial ideológico, pois traz no seu bojo simbologias e valores da autodefinição e autoavaliação que colaboram para que as mulheres negras possam perceber as circunstâncias das diversas opressões de raça, classe e gênero, vivenciadas cotidianamente.

Ainda convergindo com o raciocínio de Collins (2017), uma vez firmada essa posição ou reivindicação pela necessária compreensão interseccional das opressões, trazida pelas vozes das mulheres negras, o desafio é também manter atenção ao perigo das inclusões simbólicas, pois a aceitação dos discursos não significa, de fato, eliminação das desigualdades.

Do ponto de vista do significado do conceito de interseccionalidade para a teoria e a prática política, tanto em relação ao feminismo quanto em relação aos movimentos em geral, o desafio ainda colocado é o de ultrapassar a concepção de soma ou paralelismo de opressões (RODRIGUES, 2013), que, embora as reconheça, não consegue percebê-las como parte de uma ampla e única estrutura de dominação.

Nessa perspectiva, admite-se que a interseccionalidade se configura como importante ferramenta teórico-metodológica, pois propicia a compreensão e a visibilidade das situações concretas de exclusões e desigualdades vivenciadas pelas mulheres e pela população negra em geral. Além disso, fornece subsídios para a composição de agendas políticas destes grupos.

Por fim e, embora seja relevante a luta ímpar empreendida há décadas pelas intelectuais e ativistas aqui mencionadas, concebe-se que esta tarefa não pode ser apenas das mulheres negras. 
Cadernos de Estudos Sociais e Políticos, Rio de Janeiro, vol. 7, n 13, 2017

Submetido para avaliação em 27 de fevereiro de 2018 Aprovado para publicação em 16 de agosto de 2018 


\section{BIBLIOGRAFIA}

BAIRROS, Luíza. (1995). Nossos Feminismos Revisitados. Dados, v.3, nº 3, pp.458-463.

. (2013). Apresentação SEPPIR Dossiê mulheres negras: retrato das condições de vida das mulheres negras no Brasil. Dados, p.13.

BRASIL (2014). Instituto Brasileiro de Geografia e Estatística. Pnad. Disponível em: $<$ https://ww2.ibge.gov.br/home/estatistica/populacao/trabalhoerendimento/pnad2014/default .Shtm>. Acessado em 22/01/2017

CARNEIRO, Sueli. (2003). Mulheres em Movimento. Dados, no 17, p.p. 117-132.

(2013). Enegrecer o feminismo: A situação da mulher negra na América Latina a partir de uma perspectiva de gênero.

COLLINS, Patrícia Hill. (2016) Aprendendo com a outsider within: a significação sociológica do pensamento negro. Dados, vol.3, $\mathrm{n}^{\circ} 1$.

Patrícia Hill (2017). O que é um nome? Mulherismo, Feminismo Negro e além disso. Cadernos Pagu (51): e175118 ISSN 1809-4449.

CRENSHAW, Kimberle. (2002). Documento para o Encontro de Especialistas em Aspectos da Discriminação Racial Relativos ao Gênero. ESTUDOS FEMINISTAS (1). Pp 177-188.

DAVIS, Angela. (2013) Mulher, Raça e Classe, Gueto. (2017). Mulheres, Cultura e Política. São Paulo, Boitempo.

FERNANDES, Florestan. (1978) A Integração do Negro na Sociedade de Classes. São Paulo, Ática.

FREYRE, Gilberto. (1933) Casa-Grande \& Senzala. São Paulo, Global Editora.

GONZÁLEZ, Lélia. (1983). Racismo e sexismo na cultura brasileira. Dados, v.2.

GUIMARÃES, Alfredo S. (2012) Classes, Raças e Democracia. Editora 34. São Paulo.

HIRATA, Helena. (2014). Gênero, classe e raça interseccionalidade e consubstancialidade das relações sociais. Dados, v. 26, n. 1.

JABARDO, Mercedes. (2012) "Introducción. Construyendo puentes: en diálogo desde / con el feminismo negro", in M. Jabardo y Trafi cantes de Sueños (eds), Mapas, Madrid, p.p.32-33.

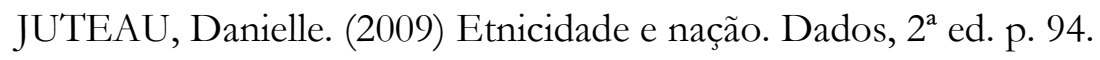


RODRIGUES, Cristiano. (2013) Atualidade do conceito de interseccionalidade para a pesquisa e prática feminista no Brasil. Anais Eletrônicos. ISSN 2179-510X. Seminário Internacional Fazendo Gênero 10. 